\title{
Intermédialités
}

Histoire et théorie des arts, des lettres et des techniques

Intermediality

History and Theory of the Arts, Literature and Technologies

\section{Index des numéros papier}

Numéro 20, supplément, automne 2012, printemps 2013

URI : https://id.erudit.org/iderudit/1023539ar

DOI : https://doi.org/10.7202/1023539ar

Aller au sommaire du numéro

Éditeur(s)

Revue intermédialités (Presses de l’Université de Montréal)

ISSN

1705-8546 (imprimé)

1920-3136 (numérique)

Découvrir la revue

Citer ce document

(2012). Index des numéros papier. Intermédialités / Intermediality, (20),

307-308. https://doi.org/10.7202/1023539ar d'utilisation que vous pouvez consulter en ligne.

https://apropos.erudit.org/fr/usagers/politique-dutilisation/ 


\section{Index des numéros papier}

$\mathrm{n}^{\circ} 1$ « naître / birth of a concept », printemps 2003

sous la direction d'Éric Méchoulan

artiste invité: Alain Escalle

$\mathrm{n}^{\circ} 2$ « raconter / telling», automne 2003

sous la direction de James Cisneros et Michèle Garneau

artiste invité: André Martin

$\mathrm{n}^{\circ} 3$ "devenir-Bergson / becoming-Bergson", printemps 2004

sous la direction de Christine Bernier et Éric Méchoulan

artiste invité: Gregory Chatonsky

$\mathrm{n}^{\circ} 4$ «aimer / loving», automne 2004

artiste invité: Bill Morrison

$\mathrm{n}^{\circ} 5$ «transmettre / transmitting», printemps 2005

artiste invitée: Élisabeth Walcker

$\mathrm{n}^{\circ} 6$ « remédier / remediation », automne 2005

sous la direction de Philippe Despoix et Yvonne Spielmann

artiste invitée: Vera Frenkel

$\mathrm{n}^{\circ} 7$ «filer / shadowing (Sophie Calle) », printemps 2006

sous la direction de Maïté Snauwaert et Bertrand Gervais

artiste invitée: Sophie Calle

$n^{\circ} 8$ « envisager / facing», automne 2006

sous la direction de Johanne Villeneuve

artiste invitée : Mieke Bal

$\mathrm{n}^{\circ} 9$ «jouer / playing», printemps 2007

sous la direction de Bernard Perron

artiste invité: Luc Courchesne

$\mathrm{n}^{\circ} 10$ " disparaître / disappearing", automne 2007

sous la direction de George Varsos et Valeria Wagner

artiste invitée: Maria Papadimitriou 
$\mathrm{n}^{\circ} 11$ «travailler / working (Harun Farocki)», printemps 2008

sous la direction de Philippe Despoix et Johanne Lamoureux

artiste invité: Harun Farocki

$\mathrm{n}^{\circ} 12$ «mettre en scène / directing ", automne 2008

sous la direction de George Brown, Gerd Hauck et Jean-Marc Larrue

artiste invité : Michel Goulet

document inédit de Paul Zumthor

$\mathrm{n}^{\circ} 13$ «programmer / programming ", printemps 2009

sous la direction de Suzanne Leblanc

artiste invité : Ruedi Baur

nº 14 «bâtir / build», automne 2009

308 sous la direction de James Cisneros et Will Straw

artiste invité : Adrian Blackwell

$\mathrm{n}^{\mathrm{0}} 15$ « exposer / displaying», printemps 2010

sous la direction de Elitza Dulguerova

artiste invité : Martin Beck

$\mathrm{n}^{\circ} 16$ « rythmer / rhythmize», automne 2010

sous la direction de Michael Cowan et Laurent Guido

artiste invité: Gustav Deutsch

$\mathrm{n}^{\circ} 17$ « reproduire / reproducing», printemps 2011

sous la direction de Suzanne Paquet

artiste invitée: Louise Merzeau

document inédit de Harold A. Innis

$\mathrm{n}^{\circ} 18$ «archiver / archiving ", automne 2011

sous la direction de Éric Méchoulan

artiste invitée: Sophie Bélair Clément

$\mathrm{n}^{\circ} 19$ «synchroniser / synchronizing», printemps 2012

sous la direction de Philippe Despoix et Nicolas Donin

artiste invitée : Anette Rose

document inédit de Glenn Gould

$\mathrm{n}^{\circ} 20$ «traverser / crossing», automne 2012 / printemps 2013 - supplément double sous la direction de Philippe Despoix, Johanne Lamoureux et Éric Méchoulan document de Paul Zumthor 